\title{
The effect of lbuprofen on female and male reproduction of the open thelyca marine shrimp, Litopenaeus
}

\author{
Jorge Alfaro-Montoya \\ Estación de Biología Marina: Lic. Juan Bertoglia Richards, Escuela de Ciencias Biológicas, Universidad Nacional, \\ Puntarenas, Costa Rica
}

Correspondence: J Alfaro-Montoya, Estación de Biología Marina: Lic. Juan Bertoglia Richards, Escuela de Ciencias Biológicas, Universidad Nacional, 100 m south of Bomba Acon, Puntarenas Centro, Puntarenas, Costa Rica. E-mail: jorge.alfaro.montoya@una.cr

\begin{abstract}
A research was designed to explore the effect of ibuprofen (IBU) as an intervening agent for prostaglandin biosynthesis on male and female reproduction of three species of Litopenaeus. Ovarian maturation was studied in L. stylirostris and L. vannamei injected periodically with IBU at 0.01 and $0.1 \mu \mathrm{g}$ $\mathrm{g}^{-1}$ body weight (b.w.) and treated for unilateral eyestalk ablation. IBU at $0.1 \mu \mathrm{g}$ induced a statistically $(P<0.05)$ higher rate of $L$. vannamei females with developing ovaries $(45 \pm 19 \%)$ as compared with controls $(12 \pm 8 \%)$ during 5 weeks; L. stylirostris did not activate vitellogenesis under this experimental protocol. IBU was also evaluated for male sexuality in L. occidentalis, L. stylirostris and L. vannamei. Periodic injections of IBU had no effect on sperm counts and spermatophore weights; however, sperm abnormalities in IBU $0.1 \mu \mathrm{g}$ treated L. occidentalis and L. stylirostris were very low. In L. stylirostris, the renovation of normal spermatophores was remarkably improved in IBU treated males as compared with controls, but in L. vannamei spermatophore deterioration was not affected. The findings of this research support the hypothesis that prostaglandins are involved in penaeid reproduction playing a negative physiological role; however, altered steroidogenic pathways could also be involved.
\end{abstract}

Keywords: Penaeidae, Litopenaeus, prostaglandins, ibuprofen, reproduction

\section{Introduction}

Prostaglandins are molecules derived from arachidonic acid and they are involved in reproduction, immune defense and ion transport, in vertebrates as well as in invertebrates (Funk 2001; Yokomizo, Izumi \& Shimizu 2001; Charlier \& Michaux 2003; Varvas, Kurg, Hansen, Järving, Järving, Valmsen, Lohelaid \& Samel 2009).

The prostaglandin-endoperoxide pathway of prostaglandin biosynthesis in non-vertebrate animals was first established in the arctic soft coral Gersemia fruticosa (Sars) by Varvas, Koljak, Järving, Pehk and Samel (1994); the key enzyme of this pathway is cyclooxygenase (COX). Recently, Varvas et al. (2009) reported the cloning and expression of COX from two amphipod crustaceans: Gammarus spp and Caprella spp.

The synthesis of prostaglandins can be inhibited with Ibuprofen (IBU), which is a non-steroidal anti-inflammatory drug that reversibly inhibits the activity of the enzyme COX by competing with its substrate (arachidonic acid) for the active sites of the enzyme (Charlier \& Michaux 2003). In the branchiopod crustacean Daphnia magna (Straus), the exposure to IBU weakly affected the transcription of the COX gene, questioning the COX-inhibiting role of IBU in neonate daphnids (Heckmann, Sibly, Connon, Hooper, Hutchinson, Maund, Hill, Bouetard \& Callaghan 2008). Complementarily, the inhibition of the COX pathway reduces estrogen biosynthesis through aromatase activity (Brueggemeier, Hackett \& Diaz-Cruz 2005; Han, Choi, Kim, Ji, Kim, Ahn, Yun, Choi, Khim, Zhang \& Giesy 2010).

Chronic exposure of D. magna to IBU induced a strong concentration-dependent reduction of reproduction (Heckmann, Callaghan, Hooper, Connon, Hutchinson, Maund \& Sibly 2007), and Hayashi, 
Heckmann, Callaghan and Sibly (2008) demonstrated the reversible effect of IBU on reproduction recovery of the same species. In D. magna and Moina macrocopa (Straus), IBU also affected reproduction negatively (Han et al. 2010). The mode of action of IBU between vertebrates and invertebrates is similar, with a targeted impact on reproduction in daphnids, primarily affecting oogenesis rather than embryogenesis, by interrupting eicosanoid (prostaglandin) metabolism and disrupting the endocrine system related to juvenile hormone metabolism and oogenesis (Heckmann et al. 2008).

The endocrine mechanism of reproduction in decapod crustaceans is not completely understood at the present. The current knowledge establishes a cascade and antagonistic hormonal control (Paran, Fierro \& Tsukimura 2010; Nagaraju 2011), involving a negative centre: the $\mathrm{x}$ organ/sinus gland from eyestalks (Nagaraju, Kumari, Prasad, Rajitha, Meenu, Rao \& Naik 2009; Nagaraju, Kumari, Prasad, Naik \& Borst 2011) and a positive centre: the brain/thoracic ganglia. A complementary centre is also involved: the mandibular organ (MO; Huberman 2000; Nagaraju 2007; Alfaro, Zúñiga, García \& Rojas 2008; Nagaraju \& Borst 2008). Serotonin (5-HT) and dopamine (DO) are neurotransmitters that regulate reproduction (Fingerman 1997; Makkapan, Maikaeo, Miyazaki \& Chotigeat 2011; Tinikul, Poljaroen, Kornthong, Chotwiwatthanakun, Anuracpreeda, Poomtong, Hanna \& Sobhon 2011). Gonadotropin releasing hormones (GnRHs) also stimulate ovarian maturation (Ngernsoungnern, Ngernsoungnern, Kavanaugh, Sobhon, Sower \& Sretarugsa 2008; Tinikul, Poljaroen, Kornthong et al. 2011; Tinikul, Poljaroen, Nuurai, Anuracpreeda, Chotwiwatthanakun, Phoungpetchara, Kornthong, Poomtong, Hanna \& Sobhon 2011; Uawisetwathana, Leelatanawit, Klanchui, Prommoon, Klinbunga \& Karoonuthaisiri 2011). Steroid hormones are also involved in ovarian development (Yano 1985, 1987; Fairs, Quinlan \& Goad 1990; Summavielle, Rocha, Reis-Henriques \& Coimbra 2003). Recently, it was reported that the retinoid $\mathrm{X}$ receptor may regulate vitellogenesis (Nagaraju, Rajitha \& Borst 2011).

The possible regulatory roles of prostaglandins (PGs) in reproduction of decapod crustaceans, including marine shrimps, have been intermittently evaluated in some species (Spaziani, Hinsch \& Edwards 1993; Spaziani, Hinsch \& Edwards 1995; Sagi, Silkovsky, Fleisher-Berkovich, Danon \& Chayoth 1995; Reddy, Reddy \& Nagaraju 2004).
In the family Penaeidae, the injection of $\mathrm{PGE}_{2}$ at $0.1 \mathrm{\mu g} \mathrm{g}^{-1}$ did not induce any effect on ovary maturation in Penaeus esculentus (Haswell) by Koskela, Greenwood and Rothlisberg (1992); however, in Penaeus monodon (Fabricius), the in vitro treatment of previtellogenic oocytes with PGE2 extracted from polychaetes induced oocyte growth. On the contrary, synthetic $\mathrm{PGE}_{2}$ did not induce the same effect (Meunpol, Duangjai, Yoonpun \& Piyatiratitivorakul 2010). In Marsupenaeus japonicus (Bate) by Tahara and Yano $(2003,2004)$, a correlation was established between the concentration of prostaglandins in ovaries $\left(\mathrm{PGF}_{2 \alpha}\right.$ and $\left.\mathrm{PGE}_{2}\right)$ and the ovarian maturation cycle, being maximum at undeveloped ovaries (approximately $20 \mathrm{pg} \mathrm{mg}^{-1}$ tissue); the hemolymph concentration showed maximum peaks at early maturing ovaries. These findings from M. japonicus disagree with Meunpol et al. (2010), who measured an opposite pattern concerning $\mathrm{PGE}_{2}$ in $P$. monodon, detecting the highest peaks from hemolymph and ovaries at mature stages. These authors suggest $\mathrm{PGE}_{2}$ acts as a vitellogenesisinducing factor and final development in penaeid shrimps. However, the biochemical significance of evaluating specific prostaglandins in invertebrates, using conventional methodologies like enzyme immunoassay (EIA) and radioimmunoassay (RIA) based on classical PGs from vertebrates and invertebrates, has been questioned, based on the possible existence of novel PGs, not yet identified (Rowley, Vogan, Taylor \& Clare 2005).

A different approach to study PGs in shrimps was recently reported by Prasertlux, Sittikankaew, Chumtong, Khamnamtong and Klinbunga (2011), who measured the expression of the prostaglandin reductase 1 gene and protein from $P$. monodon. This PG-inactivation enzyme seemed to increase during ovarian maturation, indicating that PGs were inactivated in relation to the ovarian development, in a similar way to the findings by Tahara and Yano (2004).

The reproductive strategies among decapod crustaceans are different, altering the role of PGs (Tahara \& Yano 2004); open thelyca penaeid shrimps, in particular, are free spawners with complex spermatophores and a different maturationinsemination pattern from closed thelyca species (Alfaro-Montoya 2010). Based on these controversial findings and the fact that no study has been published concerning the possible roles of prostaglandins in open thelyca penaeid shrimps, a research was designed to explore the intervention 
of the prostaglandin pathway by IBU on male and female reproduction of three species of Litopenaeus, based on previous findings from Crustacea. For the nomenclature of penaeoid shrimps, the taxonomy of Pérez-Farfante and Kensley (1997) was adopted.

\section{Materials and methods}

\section{Animals}

Litopenaeus stylirostris (Stimpson) and Litopenaeus occidentalis (Streets) were captured with gill nets by local fishermen in Golfo de Nicoya, on the Pacific coast of Costa Rica and transported for $2 \mathrm{~h}$ in containers with constant aeration to the Controlled Reproduction Laboratory at Estación de Biología Marina (EBM), Puntarenas.

Litopenaeus vannamei (Boone) [body weight (b. w.) $=20 \mathrm{~g}]$ were selected before harvesting after 3 months of commercial semi-intensive culture in earthen ponds from Golfo de Nicoya. Growth was continued at EBM in external solar-shaded tanks $\left(N=100\right.$ animals tank $\left.{ }^{-1} ; 18 \mathrm{~m}^{2}\right)$. Water was partially exchanged daily, using new water pretreated by high-pressure silica sand filtration and sedimentation. Animals were fed at 3\% b.w. of a dry feed, supplemented with fresh frozen fishes. Females and males were selected based on size and general appearance of body condition and transferred to the Controlled Reproduction Laboratory at EBM.

\section{Experimental design}

Experiments were conducted in maturation tanks (18 and $9-\mathrm{m}^{2}$ ) with a water depth of $0.50 \mathrm{~m}$ and total daily water replacement of $25-30 \%$, using new water pretreated by high pressure silica sand filtration and sedimentation. Salinity was $34 \mathrm{ppt}$, temperature fluctuated around $28-29^{\circ} \mathrm{C}$ and photoperiod was natural (13 h light: $11 \mathrm{~h}$ dark), with reduced light intensity (10-43 lx). L. stylirostris and L. vannamei females were fed at $20 \%$ and $15 \%$ b.w. day ${ }^{-1}$, respectively, with fresh frozen squids, bloodworms and fishes at equal ratios; males were fed with squids and fishes at similar ratio. The experiments were started after 1 week of acclimatisation in the experimental tanks.

\section{Ovarian maturation experiments}

During the experiments, maturation stages were registered once a week for every female based on the external close observation of ovarian size and colour, under intense light, as described by King (1948), Yano (1988), Yano, Tsukimura, Sweeny and Wyban (1988), and Tinikul, Poljaroen, Kornthong et al. (2011) with slight modifications:

Stage I: undeveloped ovary (previtellogenesis). The ovary is transparent with no distinguishable outline.

Stage II: early developing ovary (primary vitellogenesis). The ovary is visible as a thin opaque line along the dorsal central axis.

Stage III: developing ovary (secondary vitellogenesis). The ovary is visible as a thick and yellow band.

Stage IV: mature ovary (prematuration). The ovary is turgid, broad and dark red or orange. Mating and spawning are imminent at this stage.

In L. vannamei and L. stylirostris, females that reach stage IV are always receptive to natural insemination and spawning (Vaca \& Alfaro 2000; Alfaro, Zúñiga \& Komen 2004); therefore, these reproductive variables were not evaluated in this study. In order to corroborate the visual scale and vitellogenic stages, ovaries at different stages were fixed in Davidson' solution for $24 \mathrm{~h}$ and stored in $50 \%$ ethyl alcohol, according to Bell and Lightner (1988). Lobules were paraffin embedded, sectioned in cross orientation and stained in hematoxylin plus eosin at a private Laboratory: Andromeda.

\section{Litopenaeus stylirostris experiment}

Twenty six wild, stage-I females (b.w. $=30 \pm 4 \mathrm{~g}$ ) were randomly assigned to three treatments: (A) IBU $0.1 \mu \mathrm{g} \mathrm{g}^{-1}$ b.w. $(n=9)$, (B) IBU $0.01 \mu \mathrm{g} \mathrm{g}$ b. w. $(n=9)$ and (C) CONTROL $(n=8)$. Animals in treatments $\mathrm{A}$ and $\mathrm{B}$ received $0.10 \mathrm{~mL}$ of a solution, prepared by diluting a concentrated $(1.0 \mathrm{mg}$ $\mathrm{mL}^{-1}$ ) stock solution of IBU (Sigma, St. Louis, MO, USA) with sterile saline solution $(0.85 \% \mathrm{NaCl})$. Females in treatment $\mathrm{C}$ received $0.10 \mathrm{~mL}$ of the vehicle solution. Injections were applied laterally in the second abdominal segment before (weeks 0 , 4 , 5, and 6) and after unilateral eyestalk ablation (weeks 8, 9, and 10). The experiment lasted 14 weeks.

\section{Litopenaeus vannamei experiment}

Twenty one cultured, stage-I females (b.w. = $33 \pm 3 \mathrm{~g}$ ) were randomly assigned to two treatments: (A) IBU $0.1 \mu \mathrm{g} \mathrm{g}^{-1}(n=11)$ and (B) CONTROL $(n=10)$. 
Animals were treated as in the previous experiment; injections were applied before (weeks 0 and 1 ) and after eyestalk ablation (weeks 3, 4, 5, 6, and 7). The experiment lasted 7 weeks.

\section{Spermatophore quality experiments}

Litopenaeus occidentalis experiment

Twenty four wild adult males (b.w. $=33 \pm 2 \mathrm{~g}$ ) were randomly assigned to three treatments: (A) IBU $0.1 \mu \mathrm{g} \mathrm{g}^{-1} \quad(n=8)$, (B) IBU $0.01 \mu \mathrm{g} \mathrm{g} \mathrm{g}^{-1}$ $(n=8)$ and $(C)$ CONTROL $(n=8)$. Animals were treated as in the previous experiments; injections were applied at weeks 0,1 and 2; at week 3, males were manually ejaculated and spermatophores were analysed for general condition according to Alfaro-Montoya (2010), and quality in terms of sperm count, sperm abnormality and weight as described previously (Alfaro-Montoya \& Vega 2011).

\section{Litopenaeus stylirostris experiment}

Fourteen wild young males (b.w. $=26 \pm 3 \mathrm{~g}$ ) were randomly assigned to two treatments: (A) IBU $0.1 \mu \mathrm{g} \mathrm{g}^{-1}(n=8)$ and (B) CONTROL $(n=6)$. Injections were applied at weeks $0,4,5,6,7,8,9$ and 10; the spermatophore condition was weekly monitored by external observation and the spermatophore quality was measured at the end of the experimental period (12 weeks).

\section{Litopenaeus vannamei experiment}

Fifteen cultured young adult males (b.w. $=27 \pm 1 \mathrm{~g}$ ) were randomly assigned to two treatments: (A) IBU $0.1 \mu \mathrm{g} \mathrm{g}^{-1}(n=8)$ and (B) CONTROL $(n=7)$. Injections were applied at weeks $0,1,2,3$ and 4 ; the spermatophore condition was weekly monitored, artificial ejaculation was applied to stimulate spermatophore renovation according to Alfaro-Montoya (2010) and the spermatophore quality was measured at the end of the experimental period (5 weeks).

\section{Statistics}

Weekly ovarian maturation status for each experimental group was expressed graphically as absolute percentages, and the induction of vitellogenesis was evaluated using the weekly percentage of females with ovarian stages II, III, and IV. Averaged rates of developing ovaries for the experimental period were transformed with arcsine, to make the variance independent of the mean, statistically analysed with the Levene's test for homogeneity of variance and the $\mathrm{t}$-test for independent samples, at $\alpha=0.05$ (Ott 1984).

Data on spermatophore presence was expressed as absolute percentages. Data on spermatophore weight, sperm count per sample volume $(0.0001 \mathrm{~mL})$, and percentage of abnormalities were statistically analysed with the Levene's test, one way analysis of variance (ANOVA) and the post hoc tests: SNK and Tukey HSD, at $\alpha=0.05$ (Ott 1984). Sperm count and percentage abnormality data were transformed by square root of $Y+3 / 8$ (Bray, Leung-Trujillo \& Lawrence 1985) and arcsine (Leung-Trujillo \& Lawrence 1985) respectively. Statistical analyses were performed using the programme sPss (version 9; IBM, Armonk, NY, USA).

\section{Results}

The experiment with wild females of $L$. stylirostris was conducted during 14 weeks; the unilateral eyestalk ablation was performed at week 7 and IBU was injected periodically at two doses (0.01 and $\left.0.1 \mu \mathrm{g} \mathrm{g}^{-1}\right)$. Interestingly, none of the treatments activated vitellogenesis (Fig. 1), including the CONTROL group. Only 1 female in the IBU 0.01 treatment activated the ovarian maturation cycle. Survival was $50 \%$ for CONTROL and $67 \%$ for both IBU treatments.

The experiment with cultured L. vannamei, on the contrary, did activate vitellogenesis in both treatments (Fig. 2). This experiment lasted for 7 weeks; ablation was applied at week 2 and injections were also applied periodically. One week after eyestalk ablation females injected with IBU 0.1 started to develop ovaries, while the CONTROL group delayed one more week. The induction of vitellogenesis was followed for 5 weeks, and the rate of females with developing ovaries, including ovarian stages II, III and IV, was always higher for the IBU 0.1 group. The average rate of developing females was significantly superior in the IBU $0.1(45 \pm 19 \%)$ as compared with the CONTROL group $(12 \pm 8 \%$ ) at $P<0.05$. Survival was $100 \%$ for CONTROL and $82 \%$ for IBU 0.1 .

The vitellogenic stages based on the visual scale were corroborated with histological observations (Fig. 3). Stage I ovaries present oocytes in previtellogenesis, including early (Oc1) and late perinucleolus (Oc2) stages; stage II is characterized by 


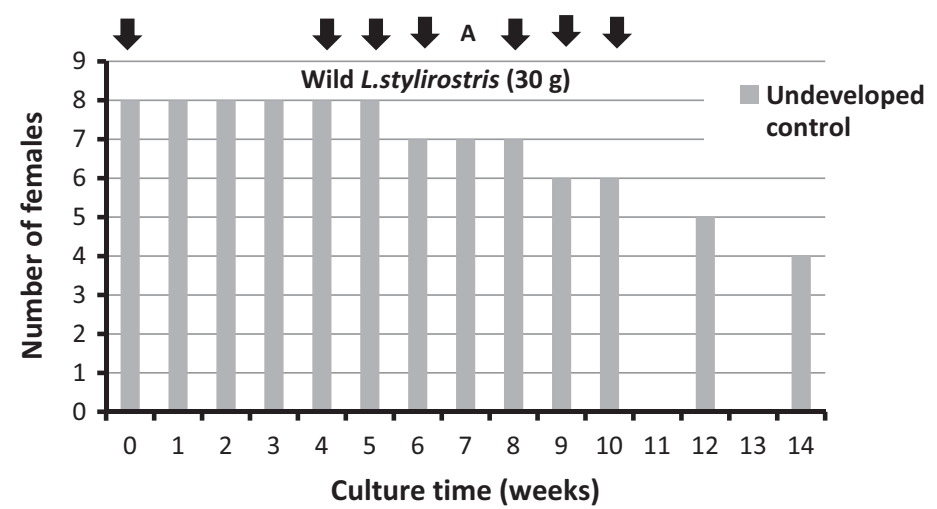

Figure 1 Ovarian maturation response of wild Litopenaeus stylirostris injected with ibuprofen at 0.01 and $0.1 \mu \mathrm{g} \mathrm{g}^{-1}$ body weight and saline control $(0.85 \% \mathrm{NaCl})$. Developing females correspond to the proportion of animals showing ovaries at stages II, III and IV. Arrows indicate application of treatments; $\mathrm{A}=$ eyestalk ablation.
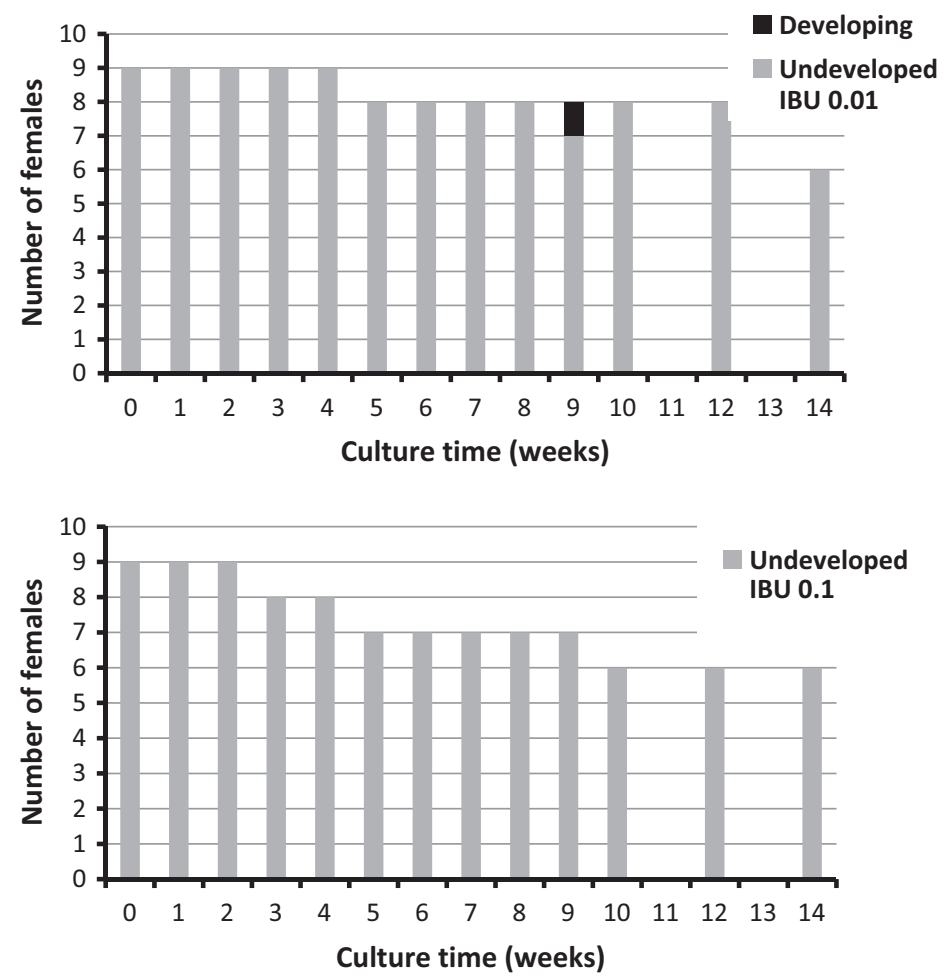

showing oocytes in primary vitellogenesis (not shown) and early secondary vitellogenesis with yolk granules (Oc3); stage III ovaries are in secondary vitellogenesis with oocytes bigger than $200 \mu \mathrm{m}$ (Oc4) and stage IV ovaries have oocytes with cortical crypts and a layer of follicle cells (Oc5).

Males of the three Litopenaeus species from the eastern Pacific were evaluated for IBU effect on their reproductive status, using spermatophore condition and quality as indicators. In wild adult L. occidentalis, no statistical differences were detected in sperm count, sperm abnormality and weight $(P>0.05)$ between IBU 0.1, IBU 0.01 and CONTROL (Fig. 4). However, a remarkable low sperm abnormality with reduced variability was measured in the IBU 0.1 group $(6.3 \pm 0.8 \%)$. Spermatophore condition in this species during the 3 weeks of experimentation was similar among treatments, characterized by normal white spermatophores. Survival was $100 \%$ for CONTROL, $75 \%$ for IBU 0.01 and 50\% for IBU 0.1.

Wild young adults of $L$. stylirostris were evaluated during 12 weeks as these males were sexually immature at the beginning of the experiment (Fig. 5a). Some males did not have fully developed petasma or spermatophores, but after 4 weeks of culture, males from both treatments had developed normal white spermatophores. In the following 


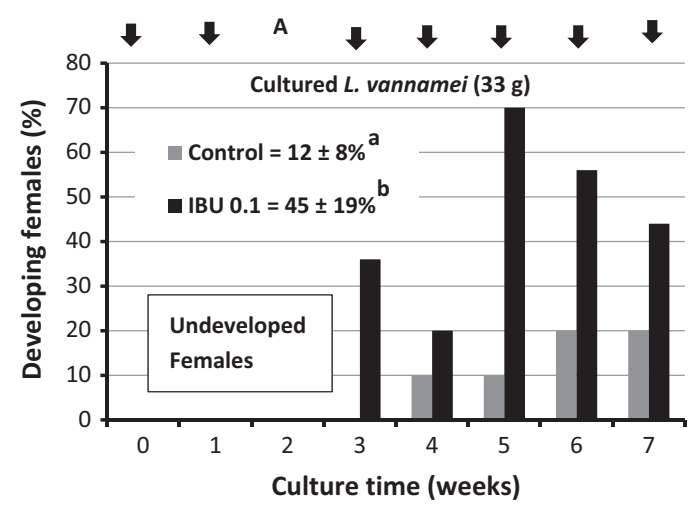

Figure 2 Ovarian maturation response of cultured Litopenaeus vannamei injected with ibuprofen at $0.1 \mu \mathrm{g} \mathrm{g}^{-1}$ body weight and saline control $(0.85 \% \mathrm{NaCl})$. Developing females correspond to the proportion of animals showing ovaries at stages II, III and IV. Arrows indicate application of treatments; A = eyestalk ablation. Mean values with different letters indicate statistical differences $(P<0.05)$.

weeks, the IBU 0.1 group showed higher rates of males with normal white spermatophores as compared with the CONTROL group. After 10-12 weeks of culture, a remarkable difference in spermatophore development was detected between treatments, reaching $86 \%$ for IBU 0.1 and $0 \%$ for CONTROL at the end of the experiment. Spermatophore condition in both treatments was similar, only normal white spermatophores were observed during the experiment. The quality of spermatophores is presented in Fig. $5 \mathrm{~b}$ after 12 weeks of culture for the IBU 0.1 group. These males developed compound spermatophores of $31 \pm 10 \mathrm{mg}$, with $823500 \pm 524119$ sperm cells and low abnormality $(21.7 \pm 12.4 \%)$. Survival was $50 \%$ for CONTROL and $88 \%$ for IBU 0.1 .

The effect of IBU was tested in cultured young adults of L. vannamei during 5 weeks (Fig. 6a). Males injected with IBU 0.1 and saline showed a similar pattern in spermatophore condition, characterized by an increasing rate of deterioration on time. At week 3, males from both treatments had spermatophores in three different conditions: normal $(\mathrm{N})$, transition to melanization $(\mathrm{N}-\mathrm{PB})$, and partially brown (PB). Artificial ejaculation was applied at week 3 to stimulate spermatophore renovation and after 2 weeks, males had developed normal white spermatophores in both treatments. Spermatophore analysis for L. vannamei is presented in Fig. 6b; both treatments generated similar high levels of sperm per compound
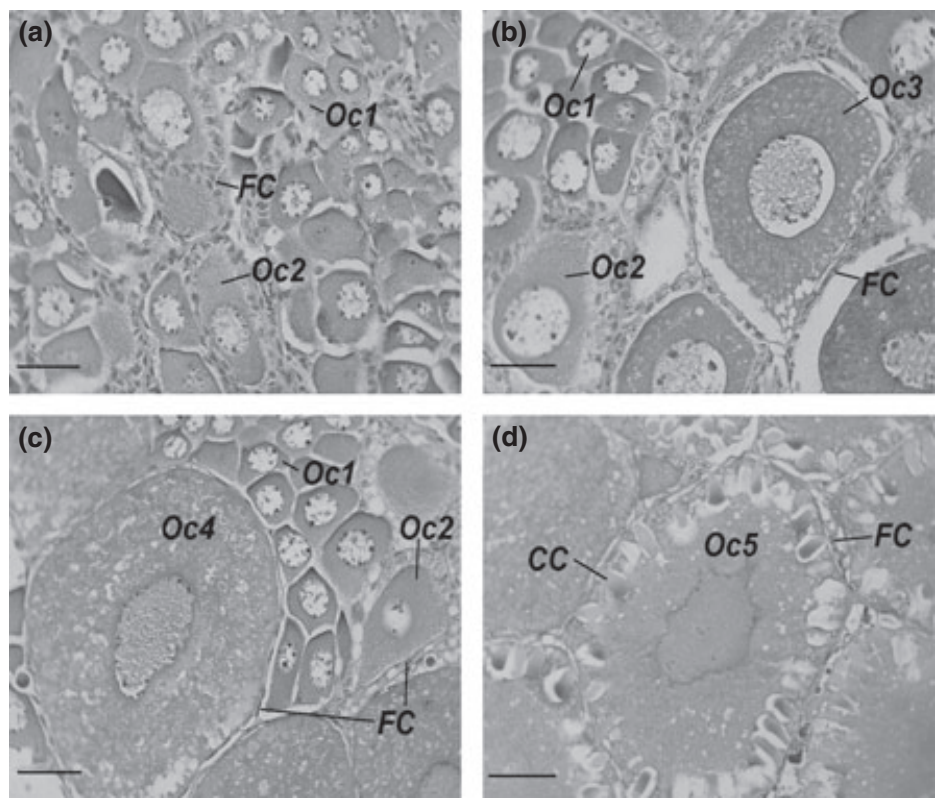

Figure 3 Corroboration of visual stages of ovarian maturation and histological observations. Plate a: stage I ovaries showing oocytes in previtellogenesis, including early (Oc1) and late perinucleolus (Oc2) stages; plate b: stage II showing oocytes in early vitellogenesis with yolk granules (Oc3); plate c: stage III ovaries in secondary vitellogenesis with oocytes bigger than $200 \mu \mathrm{m}(\mathrm{Oc} 4)$; plate d: stage IV oocytes (Oc5) with cortical crypts (CC). FC = follicle cell. Scale bars $=50 \mu \mathrm{m}$. 

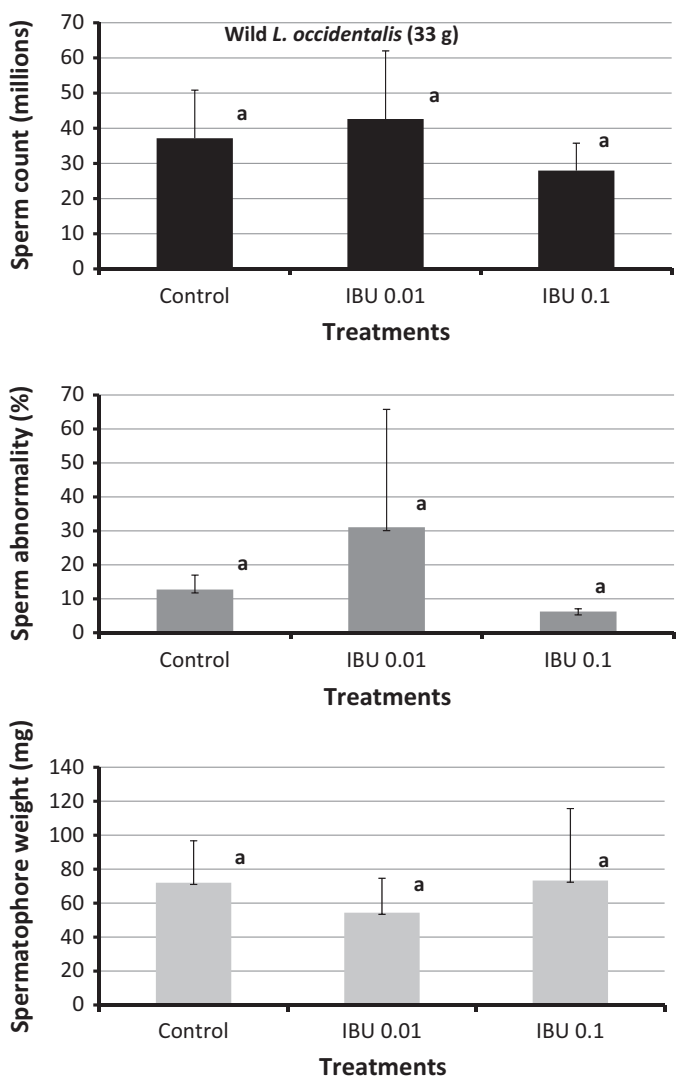

Figure 4 Spermatophore variables (mean \pm standard error) in wild Litopenaeus occidentalis injected weekly with ibuprofen at $0.1(n=3)$ and $0.01(n=5) \mu \mathrm{g} \mathrm{g}^{-1}$ body weight and saline control $(n=7)$. Bars with the same letters are not statistically different $(P>0.05)$.

spermatophore, with high rates of sperm abnormalities and similar spermatophore weights $(P>0.05)$. Survival was $57 \%$ and $62 \%$ for $\mathrm{CON}-$ TROL and IBU 0.1 respectively.

\section{Discussion}

\section{Ovarian maturation}

Females of cultured L. vannamei treated with IBU 0.1 activated a faster and higher rate of ovarian maturation as compared with the CONTROL group during 5 weeks after eyestalk ablation (Fig. 2; $P<0.05)$. Complementarily, wild $L$. stylirostris females did not activate vitellogenesis in any of the treatments, including the CONTROL group (Fig. 1). These findings suggest that IBU acted synergistically with the traditional eyestalk ablation, potentiating the activation of ovarian maturation
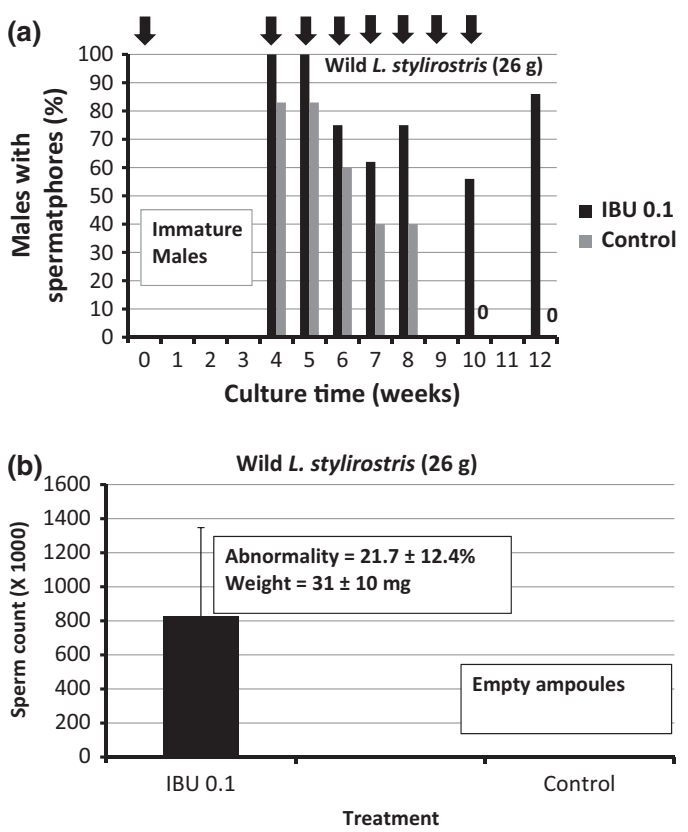

Figure 5 (a) Presence of normal spermatophores in wild Litopenaeus stylirostris injected with ibuprofen (IBU) at $0.1 \mu \mathrm{g} \mathrm{g}^{-1}$ body weight and saline control. Arrows indicate application of treatments. (b) Spermatophore variables (mean \pm standard error) at the end of the experimental period for IBU $(n=7)$ and control $(n=3)$.

in $L$. vannamei. Wild $L$. stylirostris were more sensitive to the experimental protocol, characterized by weekly injections, generating no induction of vitellogenesis during 7 weeks after eyestalk ablation. Under these stressful conditions, no effect of IBU was measured, supporting the synergistic role detected in L. vannamei. Oral administration of IBU should be evaluated as an alternative protocol in sensitive penaeid species.

The potentiating effect of IBU on ovarian maturation of eyestalk ablated females seems to support the reports by Tahara and Yano (2003, 2004) and Prasertlux et al. (2011). These authors suggested that prostaglandin concentrations decreased during ovarian development, in a similar way that the inhibition of prostaglandin synthesis by IBU at $0.1 \mu \mathrm{g} \mathrm{g}^{-1}$ seems to operate in the present study. The COX inhibiting role of these non-steroidal anti-inflammatory drugs in crustaceans is supported by previous studies. In Macrobrachium rosenbergii (Class Malacostraca), another COX inhibitor: indomethacin, blocked the synthesis of $\mathrm{PGE}_{2}$ (Sagi et al. 1995); the same 


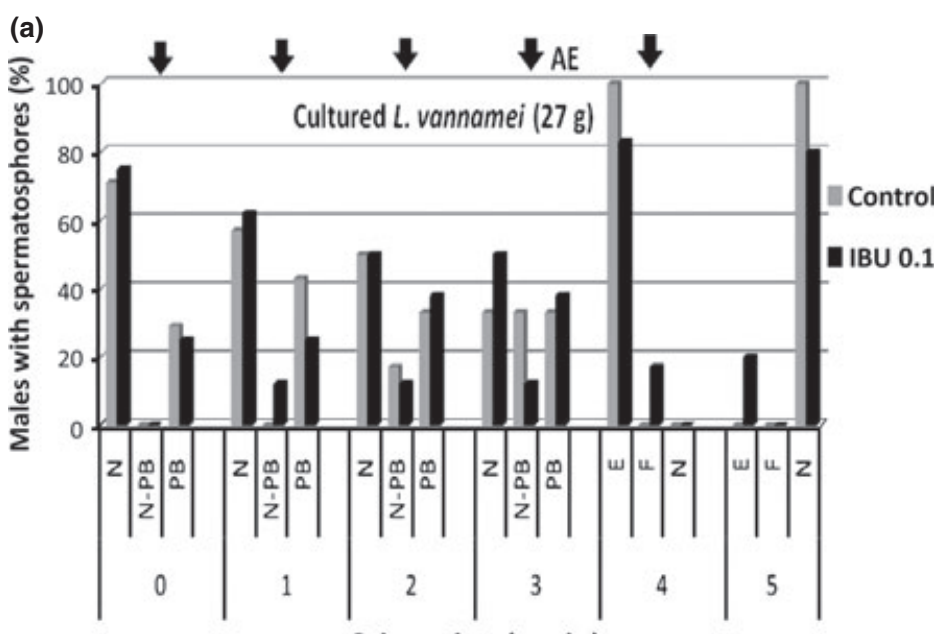

Culture time (weeks)

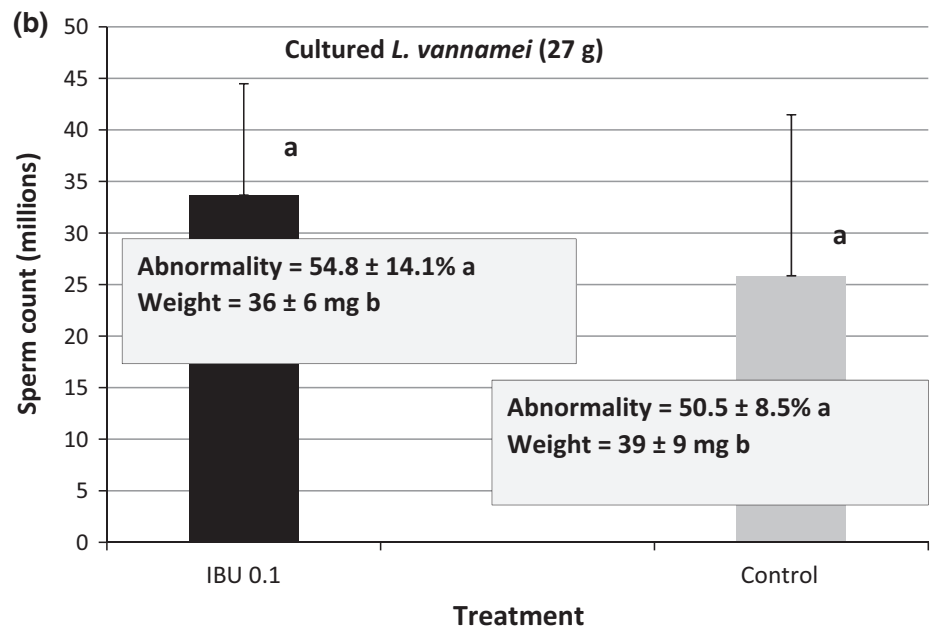

Figure 6 (a) Presence of spermatophores at different stages of deterioration in cultured Litopenaeus vannamei injected with ibuprofen (IBU) at $0.1 \mu \mathrm{g} \mathrm{g}^{-1}$ body weight and saline control. Arrows indicate application of treatments; $\mathrm{AE}=$ artificial ejaculation. (b) Spermatophore variables (mean \pm standard error) at the end of the experimental period for IBU $(n=5)$ and control $(n=4)$. Means with the same letters are not statistically different $(P>0.05)$. Spermatophore conditions: $\quad \mathrm{N}=$ normal $\quad$ white; $\mathrm{N}-\mathrm{PB}=$ slightly melanized; $\quad \mathrm{PB}=$ partially brown; $\mathrm{E}=$ empty ampoules; $\mathrm{F}=$ in formation. drug, stimulated larval settlement in the barnacle Balanus balanoides (Linnaeus; Class Maxillopoda) revised by Rowley et al. (2005).

The proposed inhibiting effect of IBU on prostaglandin metabolism of $L$. vannamei and its effect on ovarian maturation are supported with preliminary observations obtained by injecting $\mathrm{PGE}_{2}$ and $\mathrm{PGF}_{2 \alpha}$ in female L. vannamei. These molecules induced some degree of primary vitellogenesis (stage II), with a low rate of females advancing to secondary vitellogenesis (M. Quirós \& J. AlfaroMontoya, unpubl. data).

Based on the current knowledge, the induction of ovarian maturation in penaeid shrimps can be stimulated by different techniques, which intervene with the cascade of endocrine control at different levels. Therefore, application of eyestalk ablation, 5-HT, 5-HT plus spiperone, MF, GnRHs and double-stranded RNA (Ngernsoungnern et al.
2008; Paran et al. 2010; Treerattrakool, Panyim \& Udomkit 2011; Alfaro-Montoya \& Vega 2011), activate high levels of the hormonal cascade, generating high rates of induction; but the intervention at low levels of the cascade, such as steroid hormones injections, seems to have a poor effect. Similar to steroid hormones, the role of prostaglandins operates at a low level of control.

\section{Spermatophore production}

Wild adult males of L. occidentalis (Fig. 4) responded similarly in spermatophore quality $(P>0.05)$ to the repetitive injection of IBU at 0.01 and $0.1 \mu \mathrm{g} \mathrm{g}^{-1}$ b.w., and saline injection $(0.85 \% \mathrm{NaCl})$. However, the extremely low sperm abnormality registered for IBU 0.1 treated males could indicate some effect of this drug on final spermatid maturation in vas deferens (Alfaro-Montoya 2010). 
Wild young males of $L$. stylirostris (Fig. 5) treated with IBU at $0.1 \mu \mathrm{g} \mathrm{g}^{-1}$ b.w. clearly developed normal spermatophores as compared with CONTROL group. Data suggest that males in the CONTROL group were experiencing periodic elimination of spermatophores, maybe by a similar mechanism to that of $L$. vannamei, as part of the moult-dependent renovation of spermatophores (Heitzmann, Diter \& Aquacop 1993; Parnes, Raviv, Shechter \& Sagi 2006). However, the renovation mechanism did not operate efficiently in CONTROL L. stylirostris since the presence of spermatophores decreased gradually; on the other hand, males treated periodically with IBU 0.1 , seem to renovate spermatophores in a normal pattern. None of experimental males developed signs of spermatophore deterioration as reported for L. vannamei (Alfaro-Montoya 2010) and also observed in the present study with L. vannamei, suggesting that this alternative mechanism for renovation is not operational in L. stylirostris.

The quality of spermatophores produced in IBU 0.1 treated L. stylirostris is similar in sperm count and weight to L. stylirostris of similar size cultured in earthen ponds; however, sperm abnormality is quite low in the present study $(22 \%)$ as compared with pond culture (75\%; Alfaro 1993). The low abnormality measured in this study for young males $(26.4 \mathrm{~g})$ treated with IBU, is contrary to the normal pattern of spermatophore maturation, which is characterized by low sperm counts and high sperm abnormality in young males (Alfaro 1993; Alfaro-Montoya 2010).

Complementarily, the experiment with young L. vannamei generated similar high sperm counts in IBU 0.1 and CONTROL treated males, with high sperm abnormalities and similar spermatophore weights (Fig. 6). Concerning the pattern of spermatophore maturation, this species generated high sperm counts and high rates of sperm abnormalities (50\%), indicating a good adaptation to captivity but still not having fully mature reproductive systems, according to the model for male sexual maturation proposed by Alfaro-Montoya 2010.

An integrated evaluation of IBU on male sexual performance of Litopenaeus indicates that this prostaglandin-inhibiting molecule may have a stimulatory effect on male sexuality. In wild $L$. occidentalis and L. stylirostris, data suggest a possible stimulatory effect on spermatid maturation in vas deferens, based on sperm abnormality rates (Alfaro-Montoya 2010); however, this effect was not detected in cultured L. vannamei. Moreover, no negative effect on spermatophore parameters was measured in any of the three Litopenaeus species evaluated.

Previous studies have demonstrated that Litopenaeus spermatophores respond rapidly to molecules such as MF and 17- $\alpha$-methyl-testosterone (Alfaro 1996; Alfaro et al. 2008) and environmental cues (Alfaro-Montoya \& Vega 2011), improving sperm counts, rate of normal cells and spermatophore weights. Eyestalk ablation also improves the quality of spermatophores (sperm counts and spermatophore weight), but at a slow rate (Alfaro \& Lozano 1993). These evidences indicate that the intervention of the hormonal cascade for male sexuality induces positive effects regardless of the level of intervention. Therefore, the findings of this research suggest that blocking prostaglandin synthesis periodically does not affect sperm counts and spermatophore weights, but sperm abnormality may be positively affected. However, this hypothesis requires further testing, taking into account associated mechanisms such as steroidogenic pathways affected by COX inhibition.

A particularly interesting phenomenon was measured for L. stylirostris; this species demonstrated to eliminate spermatophores periodically without the deterioration mechanism described for L. vannamei (Alfaro-Montoya 2010) and IBU 0.1 stimulated the renovation of normal white spermatophores to a dramatic degree as compared with the CONTROL. Under our experimental conditions, captivity affected the normal renovation of spermatophores in wild young L. stylirostris and IBU seems to induce a positive effect on this mechanism. Complementarily, it has been previously demonstrated that cultured adult L. stylirostris renovate spermatophores periodically by artificial ejaculation (Alfaro 1993).

This is to our knowledge, the first report that explores the injection of IBU in a decapod crustacean, as a new approach to study the role of prostaglandins in reproduction. The application of IBU under the experimental protocols followed in this research allowed the study of reproductive variables in commercially important crustaceans.

The findings suggest that prostaglandins are involved in ovarian maturation as well as in spermatophore production of Litopenaeus, operating at a low level of the hormonal cascade. The synergistic effect of IBU measured on ovarian maturation of $L$. vannamei and the responses observed in male sexuality of L. occidentalis, L. stylirostris and 
L. vannamei support the hypothesis that prostaglandins are involved in penaeid reproduction playing a negative physiological role. The precise mechanisms of action are not clear at the present as IBU could be interrupting prostaglandin metabolism through the COX pathway and other pathways and acting directly or indirectly on steroidogenic pathways, as demonstrated in vertebrate cells (Brueggemeier et al. 2005; Heckmann et al. 2008; Han et al. 2010).

\section{Acknowledgments}

This contribution was supported by Ley de Pesca from the Government of Costa Rica. The author wishes to thank Luís Hernández and Captain Torres for their assistance in shrimp capture and maintenance. To unknown referees for their valuable comments.

\section{References}

Alfaro J. (1993) Reproductive quality evaluation of male Penaeus stylirostris from a grow-out pond. Journal of the World Aquaculture Society 24, 6-11.

Alfaro J. (1996) Effect of $17 \alpha$-methyltestosterone and 17 $\alpha$-hydroxyprogesterone on the quality of white shrimp Penaeus vannamei spermatophores. Journal of the World Aquaculture Society 27, 487-492.

Alfaro J. \& Lozano X. (1993) Development and deterioration of spermatophores in pond-reared Penaeus vannamei. Journal of the World Aquaculture Society 24, 522-529.

Alfaro J., Zúñiga G. \& Komen J. (2004) Induction of ovarian maturation and spawning by combined treatment of serotonin and a dopamine antagonist, spiperone in Litopenaeus stylirostris and Litopenaeus vannamei. Aquaculture 236, 511-522.

Alfaro J., Zúñiga G., García A. \& Rojas E. (2008) Preliminary evaluation of the effect of juvenile hormone III and methyl farnesoate on spermatophore quality of the white shrimp, Litopenaeus vannamei Boone, 1931 (Decapoda: Penaeidae). Revista Biología Marina y Oceanografía 43, 167-171.

Alfaro-Montoya J. (2010) The reproductive conditions of male shrimps, genus Penaeus, sub-genus Litopenaeus (open thelyca penaeoid shrimps). A review. Aquaculture 300, 1-9.

Alfaro-Montoya J. \& Vega L. (2011) The effect of environmental cues and neurotransmitters on male sexuality of the eastern Pacific Penaeus (Litopenaeus) species. Aquaculture 316, 60-67.

Bell T.A. \& Lightner D.V. (1988) A Handbook of Normal Penaeid Shrimp Histology. The World Aquaculture Society, Baton Rouge, LA, p. 114.
Bray W.A., Leung-Trujillo J. \& Lawrence A.L. (1985) Preliminary investigation on the effects of temperature, bacterial inoculation, and EDTA on sperm quality in captive Penaeus setiferus. Journal of the World Mariculture Society 16, 250-257.

Brueggemeier R.W., Hackett J.C. \& Diaz-Cruz E.S. (2005) Aromatase inhibitors in the treatment of breast cancer. Endocrine Reviews 26, 331-345.

Charlier C. \& Michaux C. (2003) Dual inhibition of cyclooxygenase-2 (COX-2) and 5-lipoxygenase (5-LOX) as a new strategy to provide safer non-steroidal antiinflammatory drugs. European Journal of Medicinal Chemistry 38, 645-659.

Fairs N.J., Quinlan P.T. \& Goad L.J. (1990) Changes in ovarian unconjugated and conjugated steroid titers during vitellogenesis in Penaeus monodon. Aquaculture 89, 83-99.

Fingerman M. (1997) Roles of neurotransmitters in regulating reproductive hormone release and gonadal maturation in decapod crustaceans. Invertebrate Reproduction and Development 31, 47-54.

Funk C.D. (2001) Prostaglandins and leukotrienes: advances in eicosanoid biology. Science 294, 1871-1875.

Han S., Choi K., Kim J., Ji K., Kim S., Ahn B., Yun J., Choi K., Khim J.S., Zhang X. \& Giesy J.P. (2010) Endocrine disruption and consequences of chronic exposure to ibuprofen in Japanese medaka (Oryzias latipes) and freshwater cladocerans Daphnia magna and Moina macrocopa. Aquatic Toxicology 98, 256-264.

Hayashi Y., Heckmann L.H., Callaghan A. \& Sibly R.M. (2008) Reproduction recovery of the crustacean Daphnia magna after chronic exposure to ibuprofen. Ecotoxicology 17, 246-251.

Heckmann L.H., Callaghan A., Hooper H.L., Connon R., Hutchinson T.H., Maund S.J. \& Sibly R.M. (2007) Chronic toxicity of ibuprofen to Daphnia magna: effects on life history traits and population dynamics. Toxicology Letters 172, 137-145.

Heckmann L.H., Sibly R.M., Connon R., Hooper H.L., Hutchinson T.H., Maund S.J., Hill C.J., Bouetard A. \& Callaghan A. (2008) Systems biology meets stress ecology: linking molecular and organismal stress responses in Daphnia magna. Genome Biology 9, R40.

Heitzmann J.C., Diter A. \& Aquacop (1993) Spermatophore formation in the white shrimp, Penaeus vannamei Boone 1931: dependence on the intermoult cycle. Aquaculture 116, 91-98.

Huberman A. (2000) Shrimp endocrinology. A review. Aquaculture 191, 191-208.

King J.E. (1948) A study of the reproductive organs of the common marine shrimp, Penaeus setiferus (Linnaeus). Biological Bulletin 94, 244-262.

Koskela R.W., Greenwood J.G. \& Rothlisberg P.C. (1992) The influence of prostaglandin $\mathrm{E}_{2}$, and the steroid hormones, $17 \alpha$-hydroxyprogesterone and $17 \beta$-estradiol on moulting and ovarian development in the tiger prawn, 
Penaeus esculentus Haswell, 1879 (Crustacea: Decapoda). Comparative Biochemistry and Physiology Part A: Physiology 101, 295-299.

Leung-Trujillo J. \& Lawrence A.L. (1985) The effect of eyestalk ablation on spermatophore and sperm quality in Penaeus vannamei. Journal of the World Mariculture Society 16, 258-266.

Makkapan W., Maikaeo L., Miyazaki T. \& Chotigeat W. (2011) Molecular mechanism of serotonin via methyl farnesoate in ovarian development of white shrimp: Fenneropenaeus merguiensis de Man. Aquaculture 321 , 101-107.

Meunpol O., Duangjai E., Yoonpun R. \& Piyatiratitivorakul S. (2010) Detection of prostaglandin E2 in polychaete Perinereis $s p$. and its effect on Penaeus monodon oocyte development in vitro. Fisheries Science 76, 281-286.

Nagaraju G.P.C. (2007) Is methyl farnesoate a crustacean hormone? Aquaculture 272, 39-54.

Nagaraju G.P.C. (2011) Reproductive regulators in decapod crustaceans: an overview. Journal of Experimental Biology 214, 3-16.

Nagaraju G.P.C. \& Borst D.W. (2008) Methyl farnesoate couples environmental changes to testicular development in the crab Carcinus maeñas. Journal of Experimental Biology 211, 2773-2778.

Nagaraju G.P.C., Kumari N.S., Prasad G.L., Rajitha B., Meenu M., Rao M.S. \& Naik B.R. (2009) Structural prediction and analysis of VIH-related peptides from selected crustacean species. Bioinformation 4, 6-11.

Nagaraju G.P.C., Kumari N.S., Prasad G.L., Naik B.R. \& Borst D.W. (2011) Computational analysis and structure predictions of $\mathrm{CHH}-$ related peptides from Litopenaeus vannamei. Integrative Biology 3, 218-224.

Nagaraju G.P.C., Rajitha B. \& Borst D.W. (2011) Molecular cloning and sequence of retinoid $\mathrm{X}$ receptor in the green crab Carcinus maenas: a possible role in female reproduction. Journal of Endocrinology 210, 379-390.

Ngernsoungnern P., Ngernsoungnern A., Kavanaugh S., Sobhon P., Sower S.A. \& Sretarugsa P. (2008) The presence and distribution of gonadotropin-releasing hormone-liked factor in the central nervous system of the black tiger shrimp, Penaeus monodon. General and Comparative Endocrinology 155, 613-622.

Ott L. (1984) An Introduction to Statistical Methods and Data Analysis. Duxbury Press, Boston, MA, p. 775.

Paran B.C., Fierro I.J. \& Tsukimura B. (2010) Stimulation of ovarian growth by methyl farnesoate and eyestalk ablation in penaeoidean model shrimp, Sicyonia ingentis Burkenroad, 1938. Aquaculture Research 41, 1887-1897.

Parnes S., Raviv S., Shechter A. \& Sagi A. (2006) Males also have their time of the month! Cyclic disposal of old spermatophores, timed by the molt cycle, in a marine shrimp. Journal of Experimental Biology 209, 4974-4983.
Pérez-Farfante I. \& Kensley B. (1997) Penaeoid and sergestoid shrimps and prawns of the world (keys and diagnoses for the families and genera). Memoires $d u$ Muséum d'Histoire Naturelle (Paris) 175, 1-233.

Prasertlux S., Sittikankaew K., Chumtong P., Khamnamtong B. \& Klinbunga S. (2011) Molecular characterization and expression of the Prostaglandin reductase 1 gene and protein during ovarian development of the giant tiger shrimp Penaeus monodon. Aquaculture 322323, 134-141.

Reddy P.S., Reddy P.R. \& Nagaraju G.P.C. (2004) The synthesis and effects of prostaglandins on the ovary of the crab Oziotelphusa senex senex. General and Comparative Endocrinology 135, 35-41.

Rowley A.F., Vogan C.L., Taylor G.W. \& Clare A.S. (2005) Review: prostaglandins in non-insectan invertebrates: recent insights and unsolved problems. The Journal of Experimental Biology 208, 3-14.

Sagi A., Silkovsky J., Fleisher-Berkovich S., Danon A. \& Chayoth R. (1995) Prostaglandin E previtellogenic ovaries of the prawn Macrobrachium rosenbergii: synthesis and effect on the level of cAMP. General and Comparative Endocrinology 100, 308-313.

Spaziani E.P., Hinsch G.W. \& Edwards S.C. (1993) Changes in prostaglandin E2 and F2 $\alpha$ during vitellogenesis in the Florida crayfish Procambarus paeninsulanus. Journal of Comparative Physiology B 163, 541-545.

Spaziani E.P., Hinsch G.W. \& Edwards S.C. (1995) The effects of prostaglandin E2 and prostaglandin F2 $\alpha$ on ovarian tissue in the Florida crayfish Procambarus paeninsulanus. Prostaglandins 50, 189-200.

Summavielle T., Rocha P.R.M., Reis-Henriques M.A. \& Coimbra J. (2003) In vitro metabolism of steroid hormones by ovary and hepatopancreas of the crustacean penaeid shrimp Marsupenaeus japonicus. Scientia Marina 67, 299-306.

Tahara D. \& Yano I. (2003) Development of hemolymph prostaglandins assay systems and their concentration variations during ovarian development in the kuruma shrimp, Penaeus japonicus. Aquaculture 220, 791-800.

Tahara D. \& Yano I. (2004) Development-related variations in prostaglandin and fatty acid content of ovary in the kuruma shrimp (Marsupenaeus japonicus). Comparative Biochemistry and Physiology Part A: Physiology 137, 631-637.

Tinikul Y., Poljaroen J., Kornthong N., Chotwiwatthanakun C., Anuracpreeda P., Poomtong T., Hanna P.J. \& Sobhon P. (2011) Distribution and changes of serotonin and dopamine levels in the central nervous system and ovary of the Pacific white shrimp, Litopenaeus vannamei, during ovarian maturation cycle. Cell and Tissue Research 345 , 103-124.

Tinikul Y., Poljaroen J., Nuurai P., Anuracpreeda P., Chotwiwatthanakun C., Phoungpetchara I., Kornthong N., Poomtong T., Hanna P.J. \& Sobhon P. (2011) Existence and distribution of gonadotropin-releasing 
hormone-like peptides in the central nervous system and ovary in the Pacific white shrimp, Litopenaeus vannamei. Cell and Tissue Research 343, 579-593.

Treerattrakool S., Panyim S. \& Udomkit A. (2011) Induction of ovarian maturation and spawning in Penaeus monodon broodstock by double-stranded RNA. Marine Biotechnology 13, 163-169.

Uawisetwathana U., Leelatanawit R., Klanchui A., Prommoon J., Klinbunga S. \& Karoonuthaisiri N. (2011) Insights into eyestalk ablation mechanism to induce ovarian maturation in the black tiger shrimp. PLoS ONE 6, e24427.

Vaca A. \& Alfaro J. (2000) Ovarian maturation and spawning in the white shrimp, Penaeus vannamei, by serotonin injection. Aquaculture 182, 373-385.

Varvas K., Koljak R., Järving I., Pehk T. \& Samel N. (1994) Endoperoxide pathway in prostaglandin biosynthesis in the soft coral Gersemia fruticosa. Tetrahedron Letters 35, 8267-8270.

Varvas K., Kurg R., Hansen K., Järving R., Järving I., Valmsen K., Lohelaid H. \& Samel N. (2009) Direct evidence of the cyclooxygenase pathway of prostaglandin synthesis in arthropods: genetic and biochemical characterization of two crustacean cyclooxygenases. Insect Biochemistry and Molecular Biology 39, 851-860.

Yano I. (1985) Induced ovarian maturation and spawning in greasyback shrimp, Metapenaeus ensis, by progesterone. Aquaculture 47, 223-229.

Yano I. (1987) Effect of 17a-hydroxy-progesterone on vitellogenin secretion in kuruma prawn, Penaeus japonicus. Aquaculture 61, 49-57.

Yano I. (1988) Oocyte development in the kuruma prawn Penaeus japonicus. Marine Biology 99, 547553.

Yano I., Tsukimura B.T., Sweeny J.N. \& Wyban J.A. (1988) Induced ovarian maturation by implantation of lobster ganglion. Journal of the World Aquaculture Society 19, 204-209.

Yokomizo T., Izumi T. \& Shimizu T. (2001) Leukotriene B4: metabolism and signal transduction. Archives of Biochemistry and Biophysics 385, 231-241. 